\title{
Impact of Substrate Outgassing on the Growth of Carbon Nanotubes Using the Single-Pulse Discharge Method
}

\author{
C. H. Su and C. H. Huang \\ Department of Mechanical Engineering, Southern Taiwan University of Science and Technology, Tainan 710, Taiwan \\ Correspondence should be addressed to C. H. Su; jssu343@gmail.com
}

Received 5 May 2016; Revised 9 July 2016; Accepted 11 July 2016

Academic Editor: Zeeshan Khatri

Copyright ( 2016 C. H. Su and C. H. Huang. This is an open access article distributed under the Creative Commons Attribution License, which permits unrestricted use, distribution, and reproduction in any medium, provided the original work is properly cited.

Carbon nanotubes (CNTs) were fabricated in air using the electrical discharge machining method. The main parameters for this process were substrate temperature, peak current $\left(I_{p}\right)$, and pulse duration $(\tau)$. The substrate was baked at $50^{\circ} \mathrm{C}$ and this temperature was maintained for $12 \mathrm{~h}$ under vacuum chamber; it was then cooled to room temperature and stored in vacuum for outgassing. During single-pulse discharge in air, the substrate was heated from room temperature to the test temperatures $\left(50\right.$ and $\left.70^{\circ} \mathrm{C}\right)$. The results indicated that the length, density, and purity of CNTs grown on outgassed substrates were better than those of CNTs grown without outgassing. Additionally, CNTs grown with $I_{p}=3 \mathrm{~A}$ and $\tau=1200 \mu$ s were of better quality than those grown with other combinations of parameters. The size of the discharge pit was effectively reduced by $30 \%(80 \mu \mathrm{m})$. This finding may help in controlling the amount of peak current used during the process, thereby reducing the problems of heat-affected zones and electrode consumption. Consequently, there was substantial improvement in the zonal selectivity and reticular density of the CNTs grown using the single-pulse discharge method.

\section{Introduction}

With improvements in applicability and processing technologies, recently various techniques for growing CNTs under atmosphere have been successfully developed. According to the literature [1-3], a peak current of 50-100 A and the use of special equipment or atmospheres are usually required for these processes. Generally speaking, although a vacuum chamber is not required, these processes are hindered by many related restrictions, including the need for a cooling system [4], the use of catalysts $[5,6]$, and continuous provision of inert gases [7-9]. In addition, the resultant CNTs are often mixed with cinders and must be purified before they can be used $[10,11]$. In order to address the shortcomings of the earlier processes and the issue of CNT purification, a new concept for growing CNTs using a single-pulse discharge method in air has been developed [12]. Recently, a reduced amount of peak current was applied during single-pulse discharge to make the discharge pits in this process as small as possible, thereby increasing the density of pits. However, after a low peak current pulse discharge in air, the kinetic energy was not enough to promote the generation of carbon nanotubes. Additionally, substrate outgassing and different substrate temperatures directly affect the temperature gradient formed under low energy of single-pulse discharge; these factors were investigated in this study to discuss the structural changes and growth mechanism of CNTs. Therefore, the aim of this study is to develop a simpler, safer, and more energy efficient technique for growing CNTs having zonal selectivity.

\section{Experimental}

The single-pulse discharge device is a triaxial and multifunctional composite step motor as shown in Figure 1. With a control program and single-pulse electronic circuits, this device has the flexibility to modulate both peak current and pulse duration. At the same time, the discharge gap between the poles can also be controlled through program design and by feedback voltage values. The device can also be used for general microdischarge machining, microdrilling, 


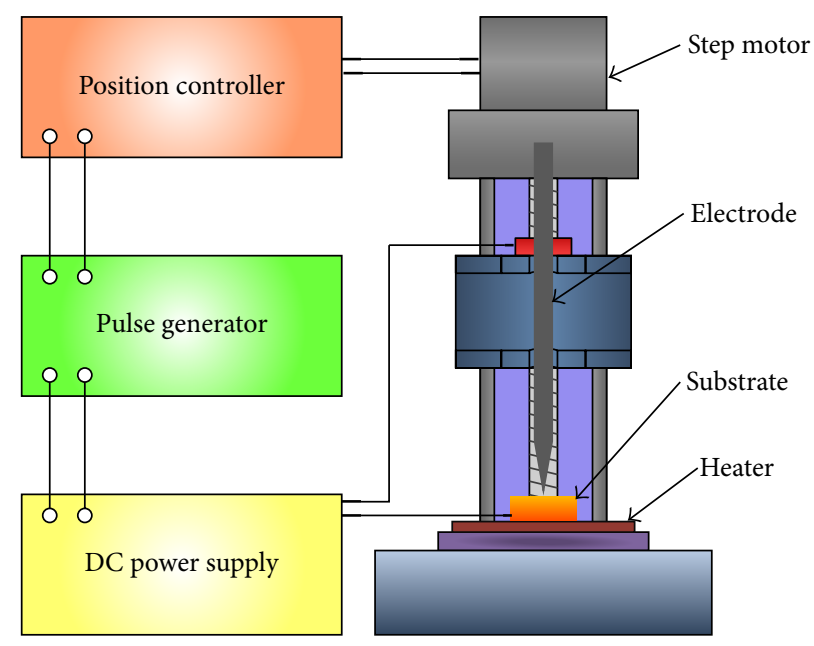

FIgURE 1: Single-pulse discharge device.

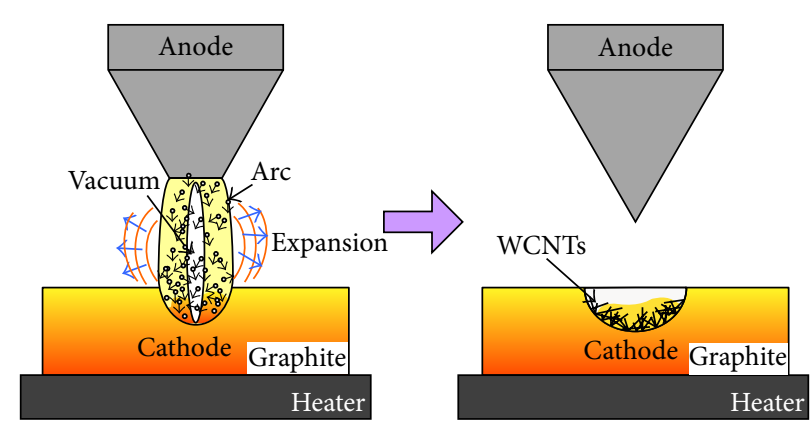

FIGURE 2: Schematic diagram of the growth of CNTs using single-pulse discharge.

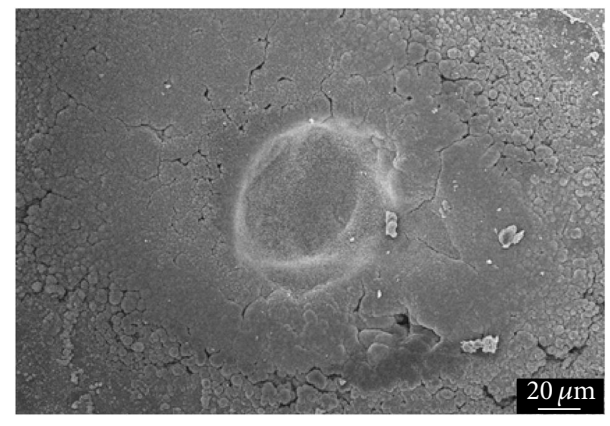

Figure 3: Discharge pit $\left(I_{p}=3 \mathrm{~A}, \tau=1200 \mu \mathrm{s}, \mathrm{RT}\right)$.

and single-pulse discharge machining. More importantly, it becomes a growth device for CNTs when the pulse control loop is modulated (Figure 2). A graphite rod having diameter $5 \mathrm{~mm}$ and length $150 \mathrm{~mm}$, with the front tip grounded to a conical shape at a $30^{\circ}$, was used as the electrode for the experiment. The graphite substrate used for the growth of CNTs with zonal selectivity was placed directly on the $X-Y$ platform, without the use of a vacuum chamber or special gases. After a single-pulse discharge, elliptical pits were created on the substrate surface by the electric arc (Figure 3 ). The
TABLE 1: Physical properties of graphite.

\begin{tabular}{lc}
\hline Apparent density $\left(\mathrm{g} / \mathrm{cm}^{3}\right)$ & 1.8 \\
Open porosity $(\%)$ & 8 \\
Compressive strength $\left(\mathrm{kg} / \mathrm{cm}^{2}\right)$ & 950 \\
Thermal conductivity $\left(\mathrm{kcal} / \mathrm{m} \cdot \mathrm{hr} \cdot{ }^{\circ} \mathrm{C}\right)$ & 100 \\
Electric resistance $(\mu \mathrm{Ohm} \cdot \mathrm{cm})$ & 1200 \\
Graphite purity $(\%)$ & 99.99 \\
\hline
\end{tabular}

thickness and shape of the substrate do not affect the results of CNT growth. Nevertheless, in order to facilitate examination by field emission scanning electron microscopy (FE-SEM, JEOL JSM-6701F), the substrates were standardized as $15 \times$ $15 \mathrm{~mm}$ squares and then outgassed by bakeout at $50^{\circ} \mathrm{C}$ for $12 \mathrm{~h}$ in a vacuum chamber. The graphite related parameters are shown in Table 1. The main experimental parameters were substrate temperature, peak current, and pulse duration. The morphology and distribution of the resulting CNTs were analyzed in order to understand the mechanism of growth. The corresponding parameter settings are presented in Table 2. 
TABLE 2: Experimental parameters.

\begin{tabular}{lc}
\hline Parameters & Value \\
\hline Substrate temperature & $\mathrm{RT}, 50^{\circ} \mathrm{C}, 70^{\circ} \mathrm{C}$ \\
Peak current $\left(I_{p}\right)$ & $2 \mathrm{~A}, 3 \mathrm{~A}$ \\
Pulse duration $(\tau)$ & $1000 \mu \mathrm{s}, 1200 \mu \mathrm{s}, 1400 \mu \mathrm{s}$ \\
Environment & In open air \\
Bakeout & Room temperature (RT) \\
\hline
\end{tabular}

\section{Results and Discussion}

3.1. Analysis of CNT Morphology and Outgassing. It has been reported by Inayoshi [13] that adsorption occurs when solid materials come into contact with gas molecules in air and that the adsorbed gas molecules are stored inside within these materials. However, when the materials are placed in a vacuum, heating causes the desorption of gas molecules from the surface of solid materials, thereby affecting the degree of vacuum of the environment. Following this principle, the substrates were placed in a vacuum oven, prior to pulsed discharge, and baked at $50^{\circ} \mathrm{C}$ for $12 \mathrm{~h}$ under a vacuum chamber. This heat treatment proactively enhanced the outgassing property of the substrate, which effectively improved the instantaneous but local vacuum formed by single-pulse discharge in air. During pulsed discharge, the substrate temperatures were set to room temperature (RT), $50^{\circ} \mathrm{C}$, and $70^{\circ} \mathrm{C}$ in order to analyze the variations in CNT growth.

The FE-SEM images of CNTs grown using the singlepulse discharge method with various peak currents $\left(I_{p}=2\right.$ and $3 \mathrm{~A}$ ) and pulse durations ( $\tau=1000,1200$, and $1400 \mu \mathrm{s})$ are shown in Figure 4. It can be seen that, without substrate outgassing, the growth of CNTs became only slightly more pronounced with $I_{p}=3 \mathrm{~A}$ and $\tau=1400 \mu \mathrm{s}$. However, with outgassed substrates, CNTs were formed with $I_{p}=2 \mathrm{~A}$ and $\tau=$ $1000 \mu \mathrm{s}$. Furthermore, for outgassed substrates, the CNTs formed with $I_{p}=3 \mathrm{~A}$ have a long, thin, and highly dense morphology. Their formability was also significantly better than those grown with the same current but without substrate outgassing. Therefore, outgassing promotes the formation of nucleation sites and provides sufficient momentum for CNT growth. This was because heating the substrate at a low temperature over a long period of time forcibly enhanced the outgassing property of the materials, which helped improve the degree of local vacuum during pulsed discharge and maintained the temperature gradient, thereby creating a conducive environment for the low-energy CNT growth process.

After outgassing, the temperature of the substrate was set to $\mathrm{RT}, 50^{\circ} \mathrm{C}$, and $70^{\circ} \mathrm{C}$ prior to pulsed discharge. Pulsed discharge was performed under different conditions, with $I_{p}=$ $3 \mathrm{~A}$ and $\tau=1000,1200$, and $1400 \mu \mathrm{s}$. CNTs were successfully grown with all combinations of parameters (Figure 5). It was observed that CNTs grown using the substrate at RT were superior to those grown at 50 and $70^{\circ} \mathrm{C}$, both in terms of length and density. This difference arises because lowenergy pulsed discharge $\left(I_{p}=3 \mathrm{~A}\right)$ only provides a limited amount of carbon molecules. Even when the environment has a higher temperature field during pulsed discharge, the absence of a carbon source prevents the growth of longer CNTs even with increased substrate temperatures. On the other hand, the combination of high temperature $\left(70^{\circ} \mathrm{C}\right)$ and high energy $\left(I_{p}=3 \mathrm{~A}, \tau=1400 \mu \mathrm{s}\right)$ provided uncrystallized, free carbon molecules having enough energy to adsorb onto the outer walls of the CNTs, leading to an increase in the amount of CNT amorphous carbon. When analyzed from the perspective of nucleation sites, changing the substrate temperature did not result in any significant difference in the nucleation process or the number of nucleation sites.

Based on the aforementioned findings, it can be concluded that substrate outgassing enhanced the formation of ambience for CNT growth using single-pulse discharge in air, and the peak current was effectively maintained below $3 \mathrm{~A}$. However, based on the experimental results, increasing substrate temperature during the process did not lead to continuous increase in CNT length but caused an increase in the amount of CNT amorphous carbon. Figure 6 shows the morphology of CNTs grown on a bakeout substrate at RT using the pulsed discharge $\left(I_{p}=3 \mathrm{~A}, \tau=1200 \mu \mathrm{s}\right)$. The length, diameter, and inner diameter of the CNTs were approximately $3.5 \mu \mathrm{m}, 6.82 \mathrm{~nm}$, and $1.8 \mathrm{~nm}$. As can be shown in the Raman spectrum in Figure 6, the higher peaks represent the background values of the graphite itself. Because of the small discharge pit diameter (only $100 \mu \mathrm{m}$ ) and the insufficient CNTs layer thickness, the manipulations of spectrum scanning, sampling, and focusing (for searching the target structures) are actually not easy. The proposed manufacturing process of CNTs has the feature of arbitrary selections of growing pits positions on a large substrate. Different from conventional methods of CNT production in batch, the density of the resulting CNTs in the pits is not high. Thus, in the Raman spectrum, the peak intensity of MWCNT is much lower than that of graphite (Figure 7). The MWCNT peak, comparing with the background graphite peak, is suppressed numerically in the plot of the Raman spectrum. However, one can still note an indicative intensity peak at $1360 \mathrm{~cm}^{-1}$ that evidently reveals the structure of the MWCNT (Multiwalled Carbon Nanotube). The HRTEM images of these CNTs are shown in Figure 8. In contrast to the substrate without baking, the CNTs outside are covered with amorphous carbon $\left(I_{p}=5 \mathrm{~A}, \tau=1200 \mu \mathrm{s}\right)$, as shown in Figure 9.

3.2. Analysis of Growth Mechanism. The growth of CNTs using the single-pulse discharge method in air can be divided into three stages: (a) generation of nanoscale protrusions, (b) nucleation, and (c) formation of CNTs, which can be better understood with Figure 8. As seen in Figure 10(a), the action of the electric field between the two poles caused explosions at the tip of the electrode. The high temperature rapidly gasified the graphite into carbon molecules, forming nanoscale protrusions at the bottom-most layer of the discharge pit. Concurrently, the explosions led to the formation of gas chambers within the discharge pit, which induced nucleation 


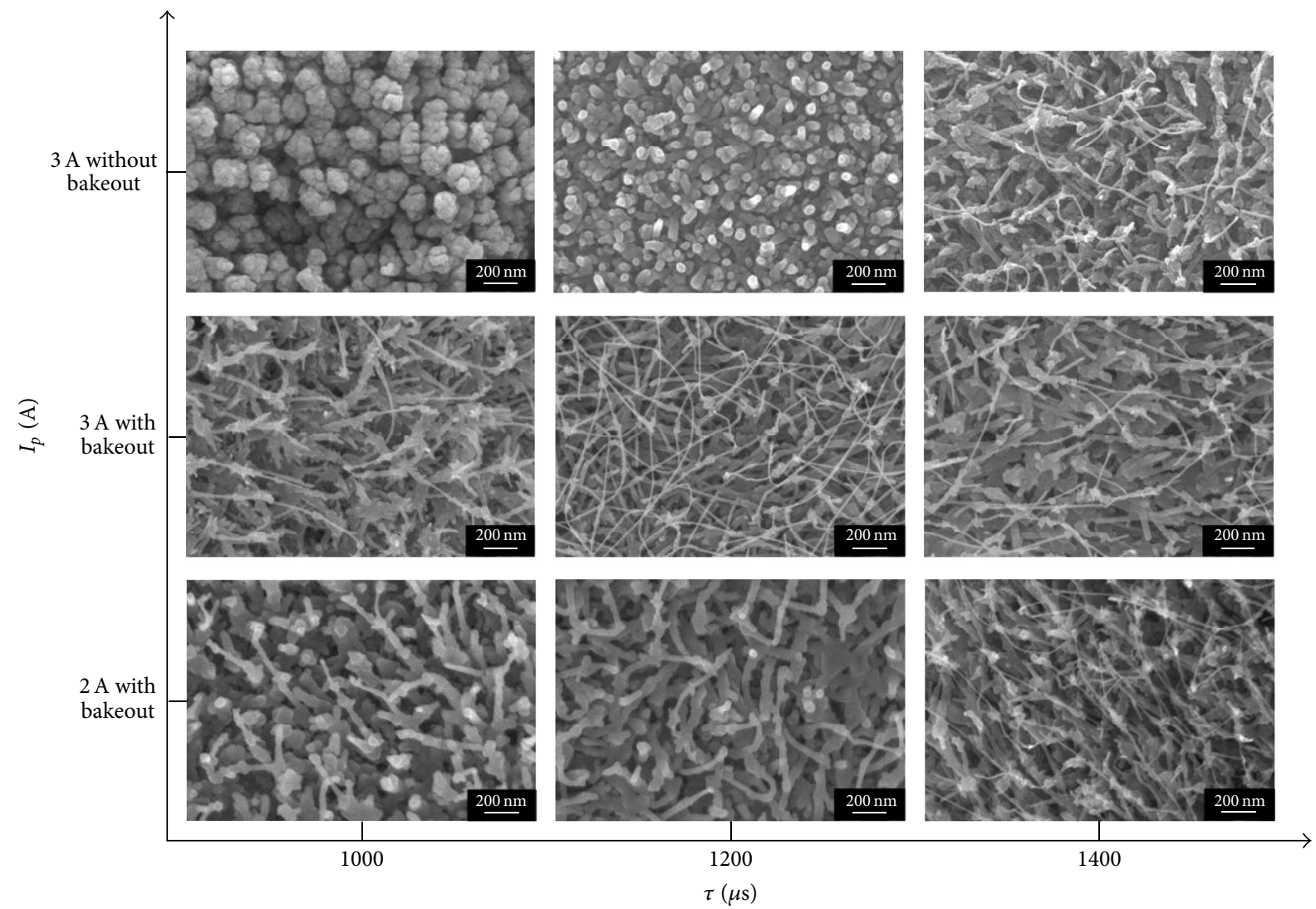

FIGURE 4: SEM morphology of CNTs grown at RT with and without substrate bakeout.

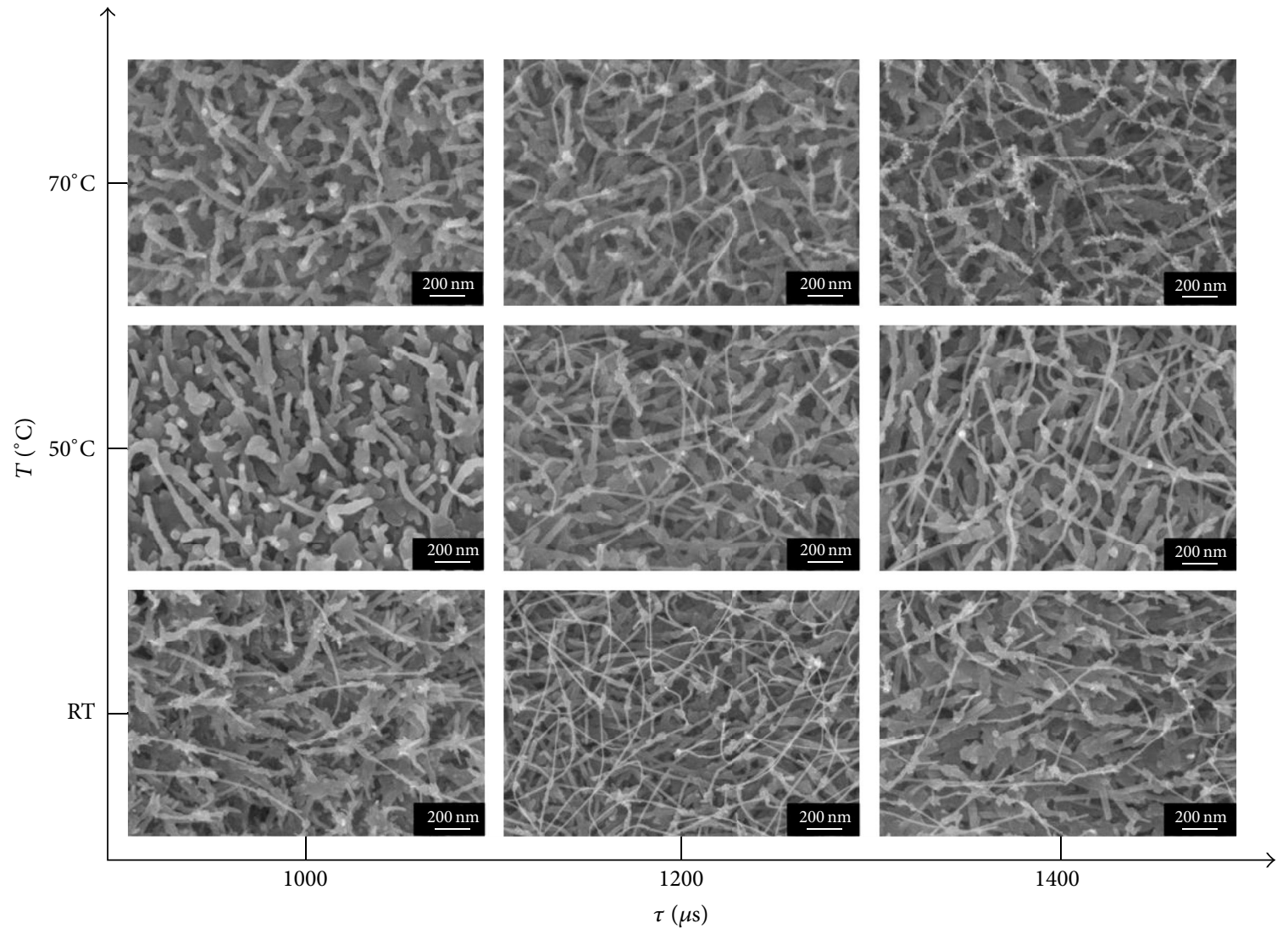

FIGURE 5: SEM morphology of CNTs grown at $I_{p}=3 \mathrm{~A}$ with different substrate temperatures (preheated substrate). 


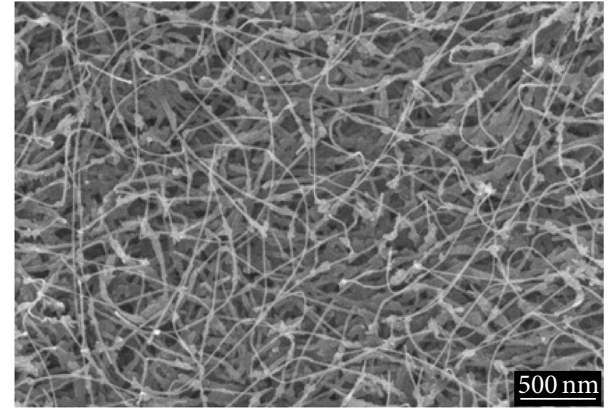

FIGURE 6: SEM morphology of CNTs $\left(I_{p}=3 \mathrm{~A}, \tau=1200 \mu \mathrm{s}, \mathrm{RT}\right)$.

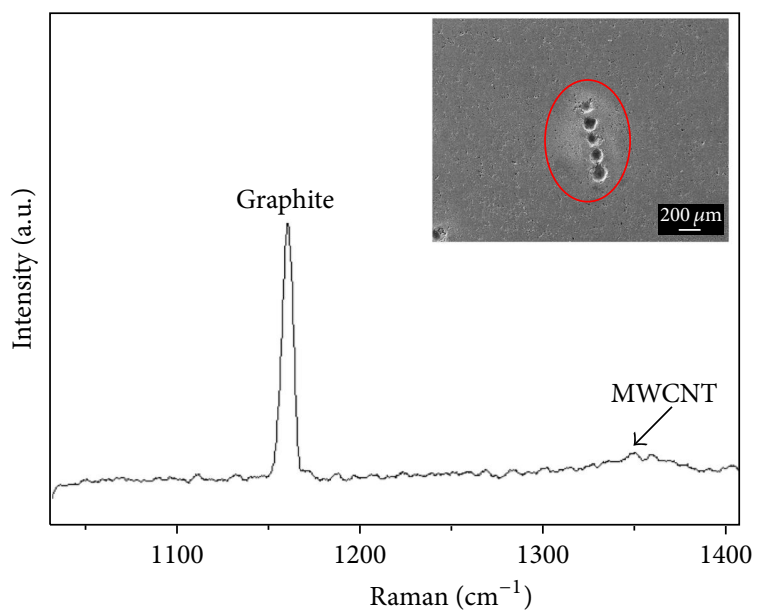

FIgURE 7: Raman spectra.

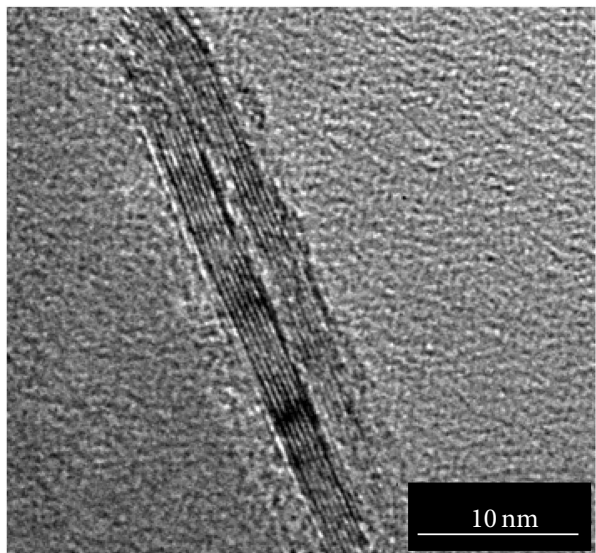

FIgURE 8: HRTEM images of CNTs $\left(I_{p}=3 \mathrm{~A}, \tau=1200 \mu \mathrm{s}, \mathrm{RT}\right)$.

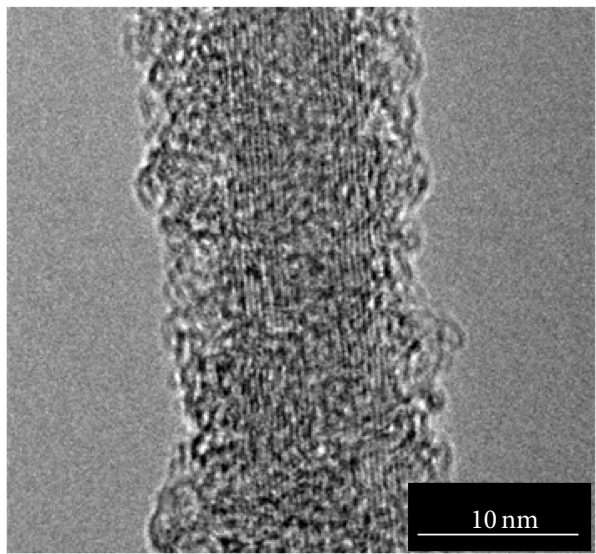

Figure 9: HRTEM images of CNTs $\left(I_{p}=5 \mathrm{~A}, \tau=1200 \mu \mathrm{s}\right.$, without substrate bakeout).

\section{Conclusion}

In this study, the experimental results and analysis showed that, during the low-energy CNTs growth process, substrate outgassing could improve the degree of local vacuum of the single-pulse discharge, effectively reduce the peak current, and reduce the diameter of the discharge pit by about $30 \%$. It was proved that substrate heating enhanced CNTs growth. This was especially true for the low-energy pulsed discharge process, where additional heat energy was provided to accelerate CNTs growth, as well as the formation and maintenance of the temperature field. In future attempts at CNT growth using single-pulse discharge, even lower energy levels should be used in the high-security operating environment to obtain CNTs with higher quality and density, such that CNTs with zonal selectivity and high-density dotmatrix arrangements can be produced to meet application requirements. 


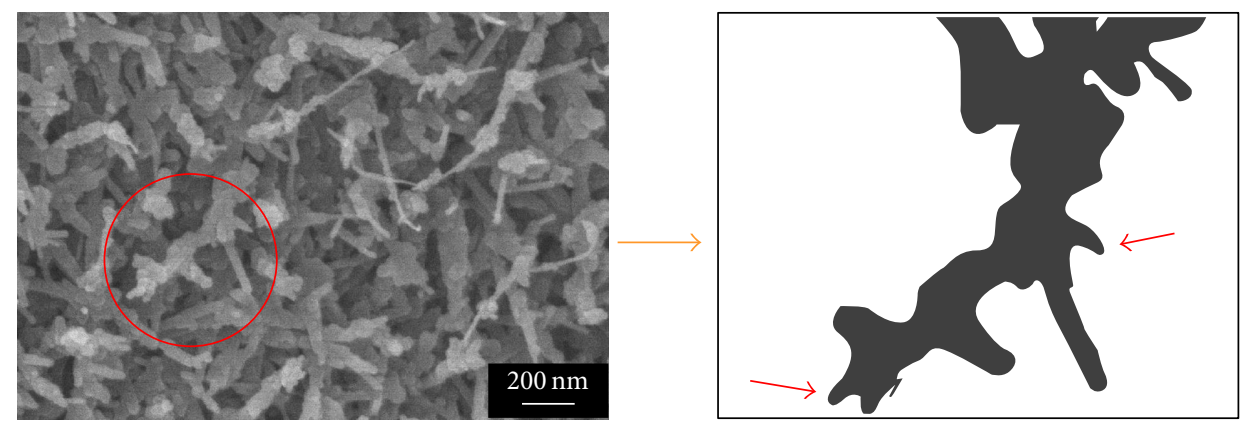

(a) Generation of nanoscale protrusions

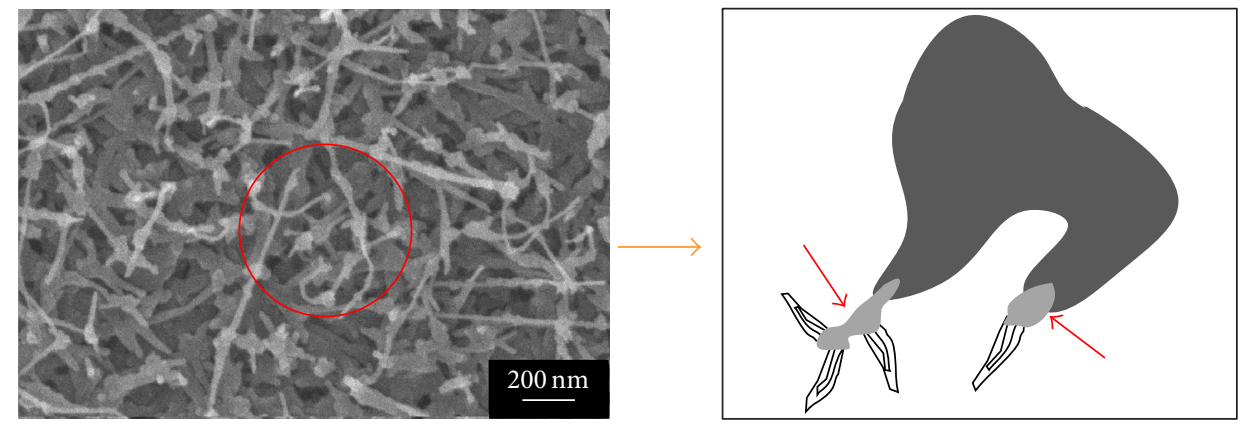

(b) Nucleation
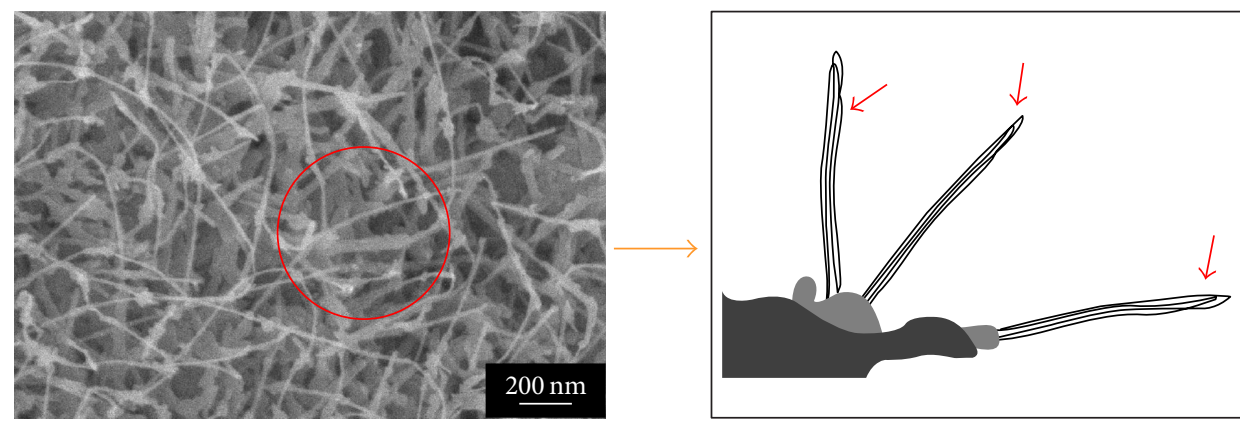

(c) Tube formation

FIGURE 10: Growth analysis of CNTs.
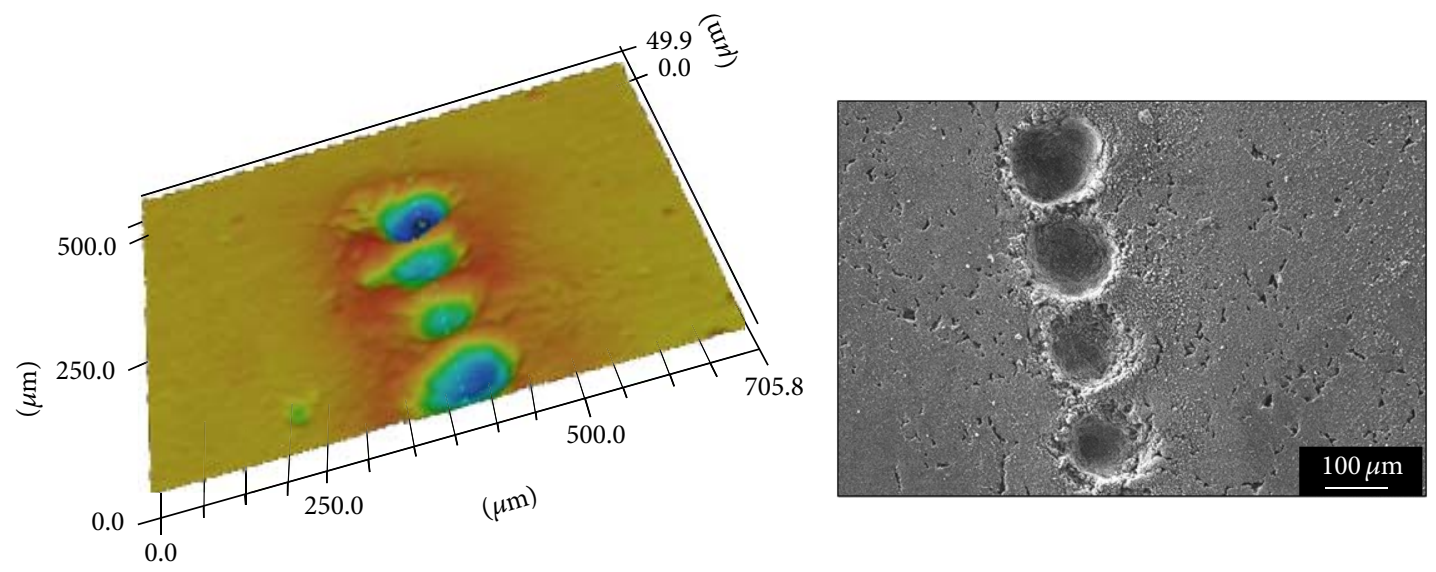

FIGURE 11: Aligned discharge pits. 


\section{Competing Interests}

The authors declare that they have no competing interests.

\section{References}

[1] N. Arora and N. N. Sharma, "Arc discharge synthesis of carbon nanotubes: comprehensive review, Diamond \& Related Materials, vol. 50, pp. 135-150, 2014.

[2] G. Tripathi, B. Tripathi, M. K. Sharma, Y. K. Vijay, A. Chandra, and I. P. Jain, "A comparative study of arc discharge and chemical vapor deposition synthesized carbon nanotubes," International Journal of Hydrogen Energy, vol. 37, no. 4, pp. 3833-3838, 2012.

[3] H. Takikawa, M. Ikeda, K. Hirahara et al., "Fabrication of singlewalled carbon nanotubes and nanohorns by means of a torch arc in open air," Physica B: Condensed Matter, vol. 323, no. 1-4, pp. 277-279, 2002.

[4] S. Yousef, A. Khattab, T. A. Osman, and M. Zaki, "Effects of increasing electrodes on CNTs yield synthesized by using arc-discharge technique," Journal of Nanomaterials, vol. 2013, Article ID 392126, 9 pages, 2013.

[5] A. A. Azira, N. F. A. Zainal, T. Soga, S. Abdullah, and M. Rusop, "Floating catalyst method for preparation of carbon nanotubes using $\mathrm{Fe} / \mathrm{Co} / \mathrm{Al}$ catalyst by thermal-CVD," Advanced Materials Research, vol. 667, pp. 525-529, 2013.

[6] Y. Su, P. Zhou, J. Zhao, Z. Yang, and Y. Zhang, "Large-scale synthesis of few-walled carbon nanotubes by DC arc discharge in low-pressure flowing air," Materials Research Bulletin, vol. 48, no. 9, pp. 3232-3235, 2013.

[7] M. Bansal, C. Lal, R. Srivastava, M. N. Kamalasanan, and L. S. Tanwar, "Comparison of structure and yield of multiwall carbon nanotubes produced by the CVD technique and a water assisted method," Physica B, vol. 405, no. 7, pp. 1745-1749, 2010.

[8] X. Cai, H. Cong, and C. Liu, "Synthesis of vertically-aligned carbon nanotubes without a catalyst by hydrogen arc discharge," Carbon, vol. 50, no. 8, pp. 2726-2730, 2012.

[9] V. V. Grebenyukov, E. D. Obraztsova, A. S. Pozharov, N. R. Arutyunyan, A. A. Romeikov, and I. A. Kozyrev, "Arc-synthesis of single-walled carbon nanotubes in nitrogen atmosphere," Fullerenes Nanotubes and Carbon Nanostructures, vol. 16, no. 56, pp. 330-334, 2008.

[10] H. Rong, Z. Liu, Q. Wu, and Y.-H. Lee, "A facile and efficient gas phase process for purifying single-walled carbon nanotubes," Current Applied Physics, vol. 10, no. 4, pp. 1231-1235, 2010.

[11] A. S. Afolabi, A. S. Abdulkareem, S. D. Mhlanga, and S. E. Iyuke, "Synthesis and purification of bimetallic catalysed carbon nanotubes in a horizontal CVD reactor," Journal of Experimental Nanoscience, vol. 6, no. 3, pp. 248-262, 2011.

[12] Y. Y. Tsai, J. S. Su, C. Y. Su, and W. H. He, "Production of carbon nanotubes by single-pulse discharge in air," Journal of Materials Processing Technology, vol. 209, no. 9, pp. 4413-4416, 2009.

[13] S. Inayoshi, "Outgassing from material in vacuum," Journal of the Vacuum Society of Japan, vol. 57, no. 8, pp. 299-302, 2014. 

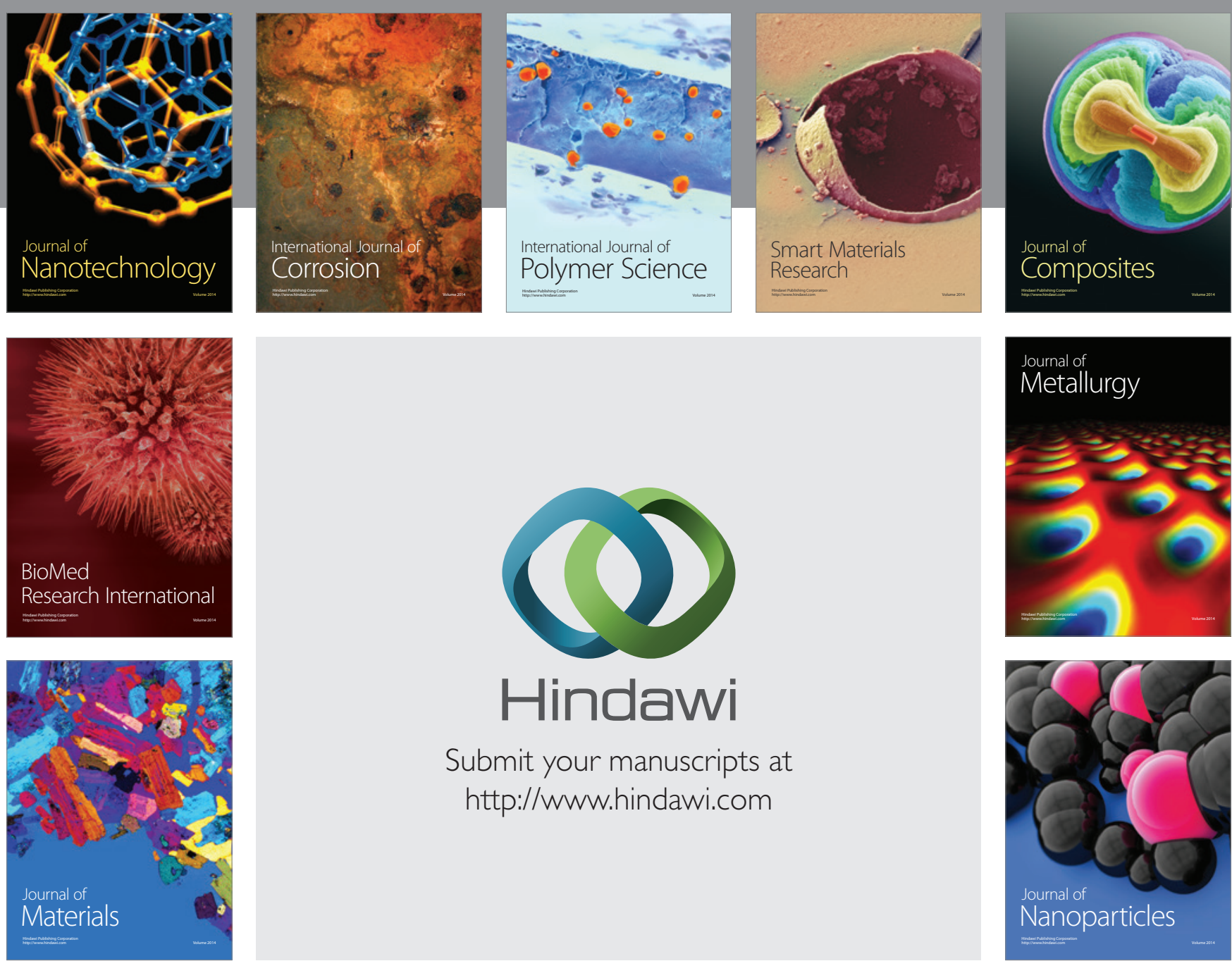

\section{Hindawi}

Submit your manuscripts at

http://www.hindawi.com

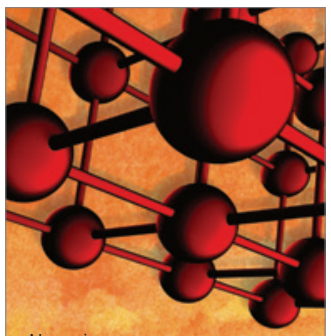

Materials Science and Engineering
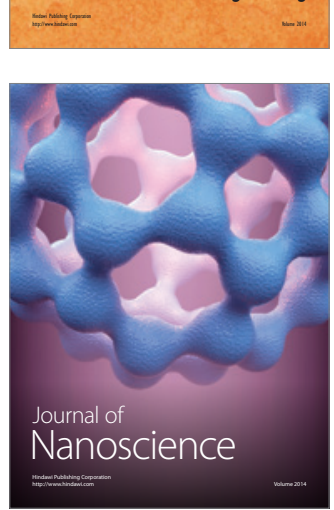
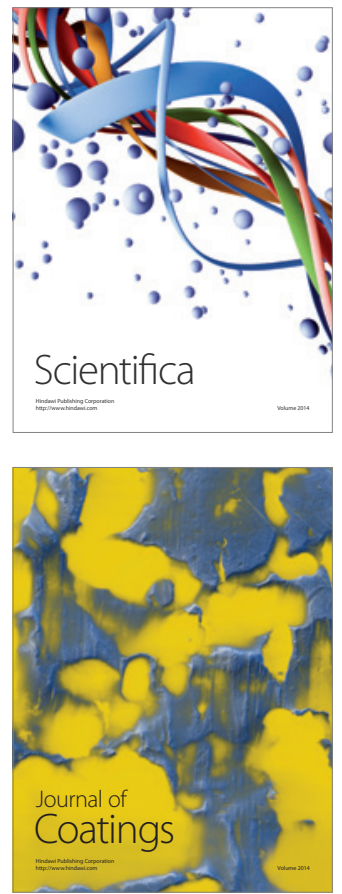
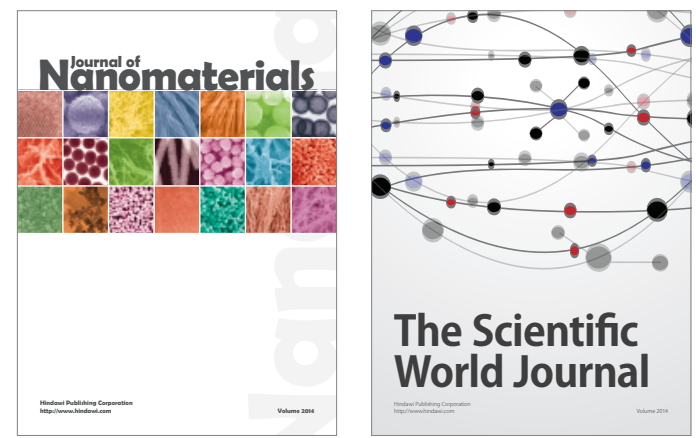

The Scientific World Journal
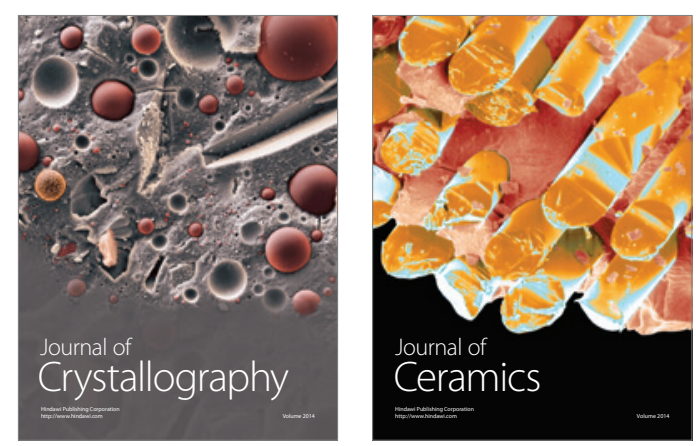
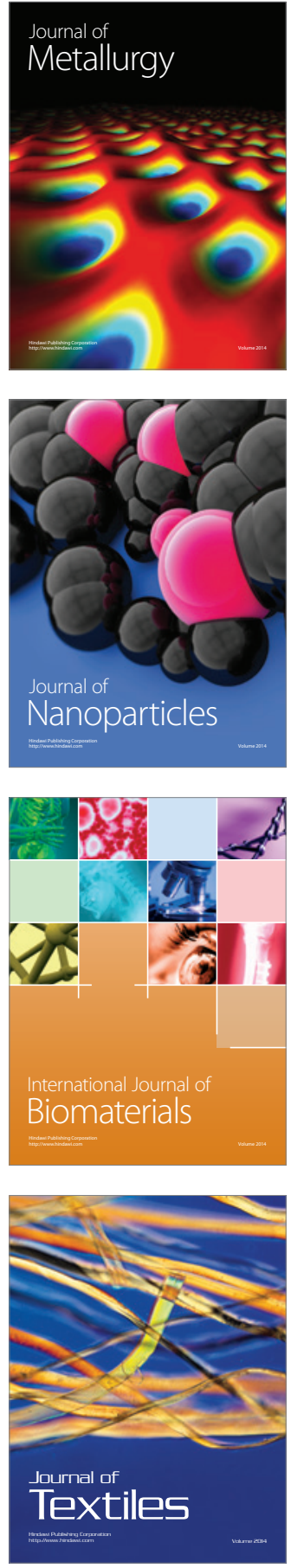